\title{
Prognostic value of adiponectin level in patients with coronary artery disease: a systematic review and meta-analysis
}

\author{
Lili Yang ${ }^{*}$ (D) Bin Li, Yuan Zhao and Zhengyi Zhang
}

\begin{abstract}
Background: Conflicting results on the prognostic value of blood adiponectin level in patients with coronary artery disease (CAD) have been reported. This meta-analysis aimed to investigate the prognostic value of elevated adiponectin level in CAD patients.

Methods: A comprehensive literature search was conducted in PubMed and Embase databases up to May 10, 2019. Studies evaluating the association between adiponectin level and major adverse cardiovascular events (death, stroke, acute coronary syndrome or coronary revascularisation), cardiovascular mortality, and all-cause mortality in CAD patients were included. Pooled multivariable adjusted risk ratios (RR) and 95\% confidence intervals (Cl) was calculated for the highest vs the lowest category of adiponectin level.
\end{abstract}

Results: Twelve studies including 10,974 CAD patients were included. Elevated adiponectin level was independently associated with higher risk of cardiovascular (RR 1.93; 95\% Cl 1.55-2.42; $p<0.001$ ) and all-cause mortality (RR 1.96; 95\% Cl 1.64-2.34; $p<0.001$ ) in CAD patients. However, CAD patients with higher adiponectin level did not significantly increase major cardiovascular events risk (RR 1.12; 95\% Cl $0.86-1.45 ; p=0.407$ ) after adjustment for potential confounders.

Conclusions: This meta-analysis indicates that elevated adiponectin level is an independent predictor of cardiovascular and all-cause mortality in CAD patients. Measurement of blood adiponectin level has potential to identify CAD patients who have high risk of death.

Keywords: Coronary artery disease, Cardiovascular events, Cardiovascular mortality, All-cause mortality, Metaanalysis

\section{Backgrounds}

Coronary artery disease (CAD) is the most common type of heart disease. In spite of advance in medical science, CAD cannot be completely prevented and avoided. Patients with $\mathrm{CAD}$ are under threat of subsequent cardiovascular events. CAD remains the globally leading cause of death among men and women [1]. However, traditional biomarkers are insufficient to predict the secondary cardiovascular events in these patients. Therefore, identification of novel predictive biomarkers is clinically urgent need for more intensive secondary prevention of cardiovascular events [2].

\footnotetext{
* Correspondence: yanglili01@tom.com

Department of General Medicine, Lanzhou University Second Hospital, No. 82 Cuiyingmen, Lanzhou 730030, Gansu Province, China
}

Biomarkers are frequently used for diagnosis and risk stratification of CAD. Adiponectin is an adipocyte-specific cytokine secreted predominantly from adipocytes [3]. Hypoadiponectinemia and hyperadiponectinemia are associated with various diseases [4]. Epidemiologic studies of healthy individuals and patients with established cardiovascular disease have suggested an association between elevated circulating adiponectin level and increased risk of cardiovascular and all-cause mortality $[5,6]$. In the presence of existing $\mathrm{CAD}$, circulating adiponectin level could also serve as a potential prognostic biomarker in these patients [7-11]. However, there are controversial findings on the prognostic value of elevated adiponectin level for predicting cardiovascular events and mortality in patients

(c) The Author(s). 2019 Open Access This article is distributed under the terms of the Creative Commons Attribution 4.0 International License (http://creativecommons.org/licenses/by/4.0/), which permits unrestricted use, distribution, and 
with CAD [12-14]. Nevertheless, the magnitude of the prognostic value varied among these studies.

No previous systematic review or meta-analysis has specially focused on the prognostic value of elevated adiponectin level in CAD patients. Given these heterogeneous findings, we performed this meta-analysis to investigate the prognostic role of elevated adiponectin level for predicting MACE and survival outcomes in CAD patients.

\section{Methods}

\section{Literature search}

This meta-analyses followed the Preferred Reporting Items for Systematic Reviews and Meta-analyses (PRISMA) [15]. Two authors independently searched the articles indexed in PubMed and Embase databases from their inceptions to May 10, 2019. Search keywords used for literature search included: "adiponectin" AND "coronary artery disease" OR "coronary heart disease" OR "myocardial infarction" OR "acute coronary syndromes" OR "angina" AND "death" OR "mortality" OR "cardiovascular events". The detaied search strategy is showed in Additional file 1. Additionally, reference lists of included studies and related reviews were also manually reviewed to identify additional studies.

\section{Study selection}

Studies satisfied the all the following criteria were included: 1) original longitudinal studies enrolling CAD patients, 2) baseline blood adiponectin level as exposure, and, 3) reported multivariable adjusted risk ratios (RR) or hazard ratios (HR) or odds ratio (OR) with their corresponding 95\% confidence intervals (CI) of all-cause or cardiovascular mortality and/or major adverse cardiovascular events (MACE) for the categorical adiponectin level during the follow-up. Exclusion criteria included the following: 1) population were not restricted in CAD patients or coexisting with $\mathrm{CAD}$ and other specific diseases, 2) reported risk estimate by continuous adiponectin level, 3) provided unadjusted risk estimate, and, 4) meeting abstracts, commentaries, reviews or duplicate publications.

\section{Data extraction and quality assessment}

Two authors independently extracted the data and evaluated the study quality. Disagreements among two authors in data extraction and quality assessment were resolved through discussion. Data extracted from the eligible studies included first author's surname, year of publication, country/region, study design, type of CAD, number of participants, percentage of men, mean age or age range at enrollment, cutoff value of adiponectin, mean or median follow-up, type of outcome, number of events, fully adjusted risk estimate, and adjustment of variables in the multivariate analysis. The methodological quality of all eligible studies was evaluated using the nine-star Newcastle-
Ottawa Scale (NOS) for cohort studies [16], which bases its assessment on selection of the study groups, comparability of study groups, and ascertainment of the outcome. Studies awarding 7 stars or over were deemed as high quality.

\section{Statistical analysis}

All statistical analyses were performed using STATA 12.0 (STATA Corp LP, College Station, TX, USA). The multivariable adjusted risk estimate was pooled for the highest vs the lowest category of adiponectin level. For studies reporting risk estimate by the lowest vs the highest adiponectin level, we recalculated it for the highest vs the lowest category. Heterogeneity among studies was quantitatively assessed using the Cochrane $\mathrm{Q}$ statistic $(p<0.10$, statistically significant heterogeneity) and the $\mathrm{I}^{2}$ statistic ( $\geq 50 \%$, statistically significant heterogeneity). A random effect model was applied in the case of significant heterogeneity. Otherwise, we chose a fixed-effect model. Begg's test [17] and Egger's test [18] were used to examine publication bias, with a $p$-value $<0.10$ suggesting statistical significance. Moreover, we scheduled a subgroup analysis according to sample sizes, type of CAD, length of follow-up, adjustment of left ventricular ejection fraction and NOS score. Sensitivity analysis was conducted by omitting one study at each turn to check the reliability of the pooling risk estimates.

\section{Results}

\section{Search results and study characteristics}

The study selection process is summarized in Fig. 1. Our initial literature search yielded 886 potentially relevant citations. Among the citations, 417 duplicates were excluded. After reviewing the titles and abstracts, 402 articles were excluded. The remaining 69 full-text articles were retrieved for detailed assessment. After removing all studies that did not satisfy the inclusion criteria, twelve studies [7-14, 19-22] were finally included in the current meta-analysis.

Table 1 summarizes the main characteristics of the included studies. All the included studies were prospective designs and published from 2006 to 2016. The sample size ranged from 77 to 3931, with a total of 10,974 CAD patients. The length of mean or median follow-up ranged from 12 months to 8.1 years. Overall, there were 1818 MACE, 842 all-cause and 285 cardiovascular death in the selected studies. Nine studies $[7,8,11-14,19-21]$ had a score of 7 stars or over (Table 2), indicating a relatively high quality.

\section{Impact of elevated adiponectin level on MACE}

Eight studies $[8-14,20]$ reported the association between elevated adiponectin level and MACE (Fig. 2). The pooled RR of MACE was $1.12(95 \%$ CI $0.86-1.45 ; p=0.407)$ for 


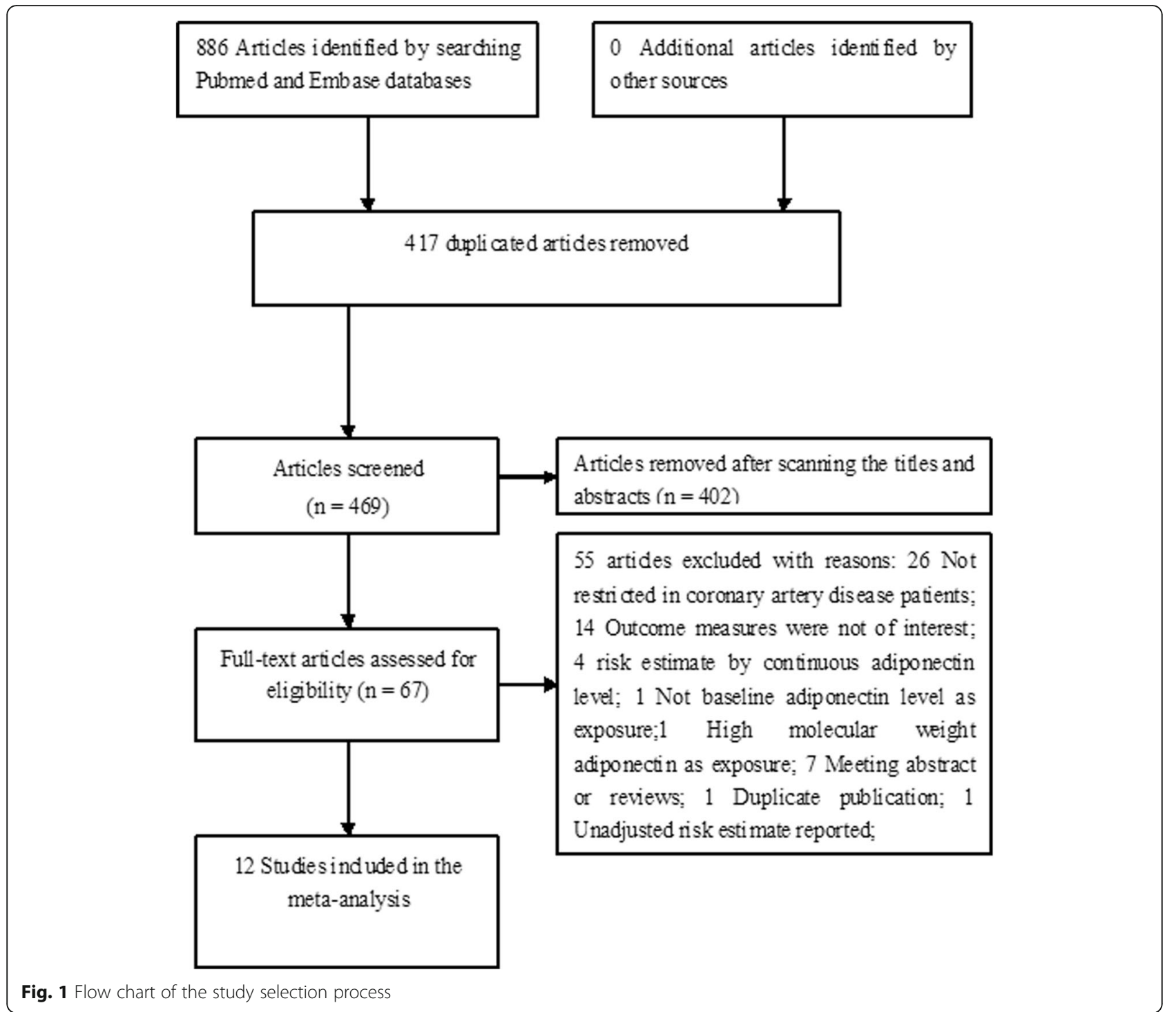

the highest vs the lowest category of adiponectin level in a random effect model, with significant heterogeneity $\left(\mathrm{I}^{2}=\right.$ $78.1 \% ; p<0.001)$. Sensitivity analyses indicated no significant alterations in the original pooled risk estimate when any study was excluded from the analysis (data not shown). The Begg's test $(p=0.902)$ and the Egger's test $(p=0.746)$ did not show evidence of publication bias. Subgroup analysis showed that the pooled RR of MACE was 1.23 (95\% CI 1.03-1.47; $p=0.020$ ) and 1.31 (95\% CI 1.02$1.68 ; p=0.033$ ) in patients with acute coronary syndrome (ACS) and follow-up more than 3 years, respectively. The detailed results of subgroup analysis are shown in Table 3.

\section{Impact of elevated adiponectin level on all-cause and cardiovascular mortality}

Elevated adiponectin level for predicting all-cause mortality was reported in 6 studies [7, 13, 14, 19, 21, 22]
(Fig. 3a). The pooled RR of all-cause mortality was 1.96 (95\% CI 1.64-2.34; $p<0.001$ ) for the highest vs the lowest category of adiponectin level in a fixedeffect model, without significant heterogeneity $\left(\mathrm{I}^{2}=\right.$ $35.8 \% ; p=0.168)$. Publication bias was not found according to the results of the Begg's test $(p=0.348)$ and the Egger's test $(p=0.194)$. Four studies [7, 12, $19,21]$ reported the prognostic value of elevated adiponectin level for predicting cardiovascular mortality. As shown in Fig. 3b, a fixed-effect model was selected because there was no significant heterogeneity $\left(\mathrm{I}^{2}=\right.$ $13.5 \% ; p=0.325)$. The pooled $\mathrm{RR}$ of cardiovascular mortality was 1.93 (95\% CI $1.55-2.42 ; p<0.001)$ for the highest vs the lowest category of adiponectin level. Sensitivity analysis slightly changed the original pooled risk estimates of all-cause or cardiovascular mortality (data not shown). 


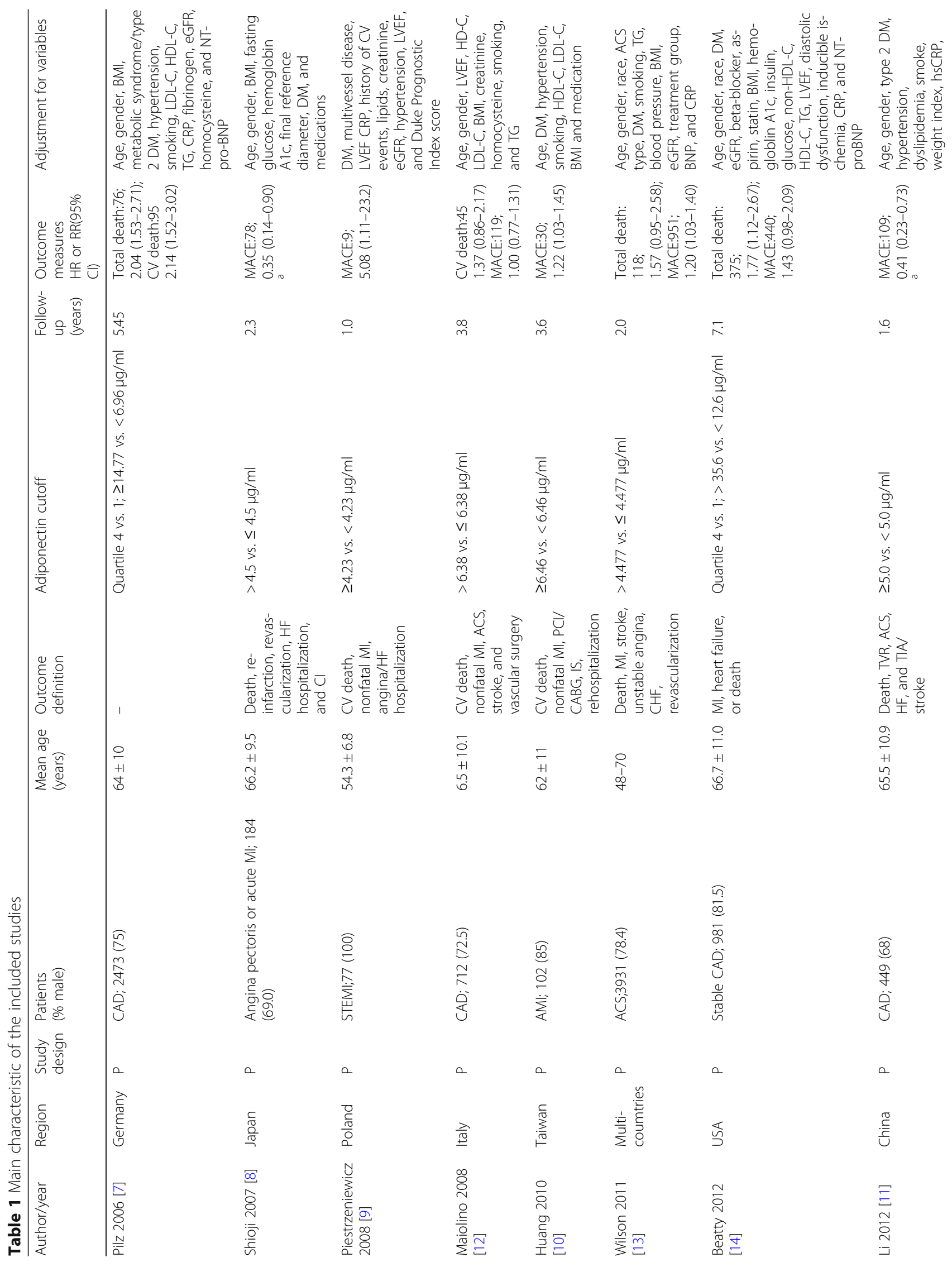




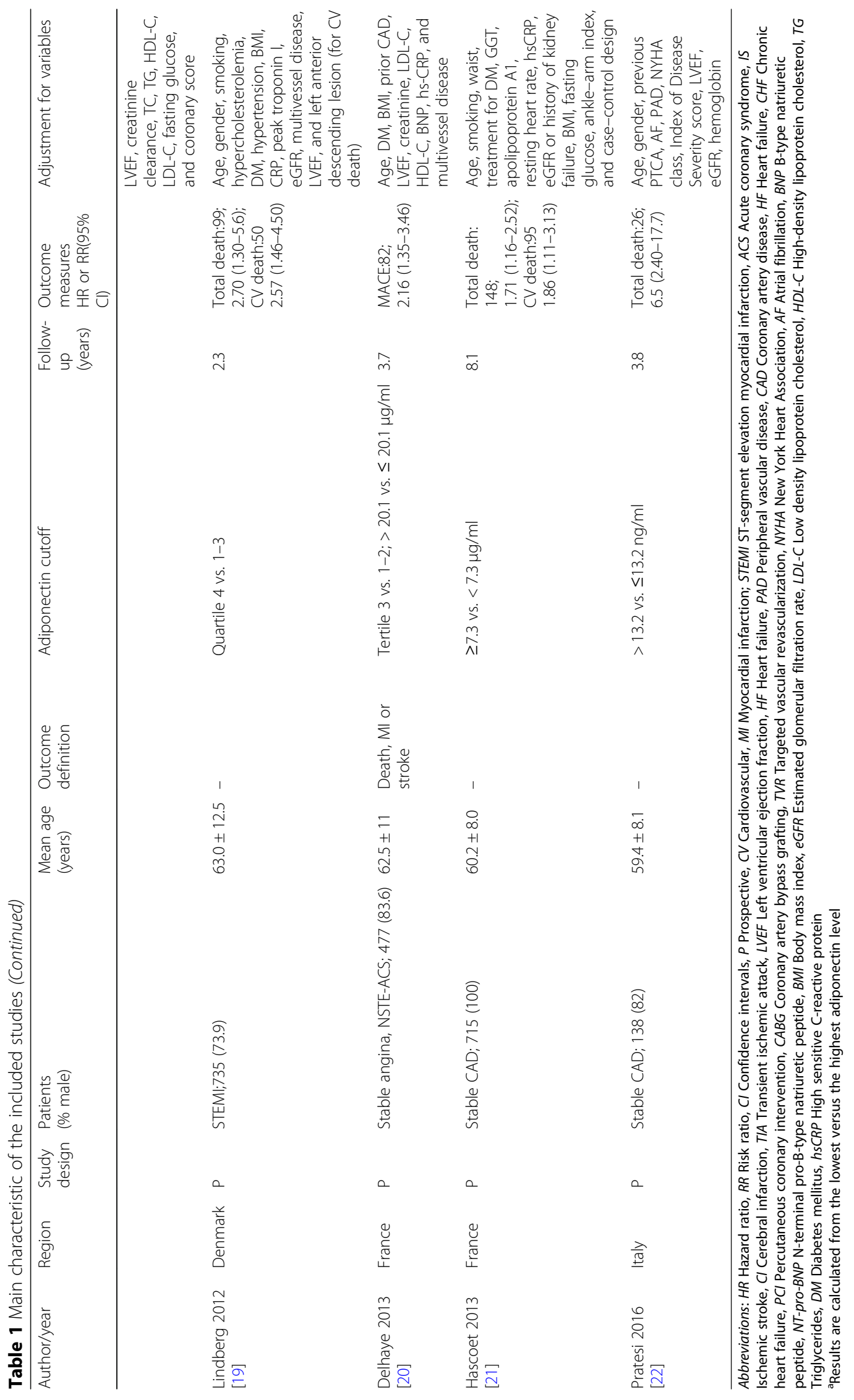


Table 2 Quality assessment of the included studies

\begin{tabular}{|c|c|c|c|c|c|c|c|c|c|}
\hline Author/Year & $\begin{array}{l}\text { Representativeness } \\
\text { of the exposed } \\
\text { cohort }\end{array}$ & $\begin{array}{l}\text { Selection } \\
\text { of the } \\
\text { non } \\
\text { exposed } \\
\text { cohort }\end{array}$ & $\begin{array}{l}\text { Ascertainment } \\
\text { of exposure }\end{array}$ & $\begin{array}{l}\text { Demonstration } \\
\text { that outcome } \\
\text { was not } \\
\text { present at } \\
\text { study start }\end{array}$ & $\begin{array}{l}\text { Comparability } \\
\text { of cohorts on } \\
\text { the basis of the } \\
\text { design or } \\
\text { analysis }\end{array}$ & $\begin{array}{l}\text { Assessment } \\
\text { of outcome }\end{array}$ & $\begin{array}{l}\text { Enough } \\
\text { follow- } \\
\text { up pe- } \\
\text { riods ( } \geq \\
5 \text { years) }\end{array}$ & $\begin{array}{l}\text { Adequacy } \\
\text { of follow- } \\
\text { up of } \\
\text { cohorts }\end{array}$ & TotalNOS \\
\hline Pilz 2006 [7] & $\star$ & $\star$ & $\star$ & $\star$ & $\star$ & $\star$ & $\star$ & $\star$ & 8 \\
\hline Shioji 2007 [8] & $\star$ & $\star$ & $\star$ & $\star$ & $\star \star$ & $\star$ & & $\star$ & 8 \\
\hline $\begin{array}{l}\text { Piestrzeniewicz } \\
2008 \text { [9] }\end{array}$ & & $\star$ & $\star$ & $\star$ & $\star$ & $\star$ & & $\star$ & 6 \\
\hline $\begin{array}{l}\text { Maiolino } \\
2008 \text { [12] }\end{array}$ & $\star$ & $\star$ & $\star$ & $\star$ & $\star$ & $\star$ & $\star$ & $\star$ & 8 \\
\hline $\begin{array}{l}\text { Huang } \\
2010 \text { [10] }\end{array}$ & & $\star$ & $\star$ & $\star$ & $\star$ & $\star$ & & $\star$ & 6 \\
\hline $\begin{array}{l}\text { Wilson } \\
2011 \text { [13] }\end{array}$ & & $\star$ & $\star$ & $\star$ & $\star \star$ & $\star$ & & $\star$ & 7 \\
\hline $\begin{array}{l}\text { Beatty } \\
2012[14]\end{array}$ & & $\star$ & $\star$ & $\star$ & $\star \star$ & $\star$ & $\star$ & $\star$ & 8 \\
\hline Li 2012 [11] & $\star$ & $\star$ & $\star$ & $\star$ & $\star$ & $\star$ & & $\star$ & 7 \\
\hline $\begin{array}{l}\text { Lindberg } \\
2012 \text { [19] }\end{array}$ & & $\star$ & $\star$ & $\star$ & $\star \star$ & $\star$ & & $\star$ & 7 \\
\hline $\begin{array}{l}\text { Delhaye } \\
2013 \text { [20] }\end{array}$ & $\star$ & $\star$ & $\star$ & $\star$ & $\star$ & $\star$ & & $\star$ & 7 \\
\hline $\begin{array}{l}\text { Hascoet } \\
2013 \text { [21] }\end{array}$ & & $\star$ & $\star$ & $\star$ & $\star$ & $\star$ & $\star$ & $\star$ & 7 \\
\hline $\begin{array}{l}\text { Pratesi } \\
2016 \text { [22] }\end{array}$ & & $\star$ & $\star$ & $\star$ & $\star$ & $\star$ & & $\star$ & 6 \\
\hline
\end{tabular}

NOS Newcastle-Ottawa Scale

\section{Discussion}

The current meta-analysis suggests that an elevated total adiponectin level is possibly an independent predictor of cardiovascular and all-cause mortality in CAD patients. When compared with those with the lowest circulating total adiponectin level, CAD patients with the highest total adiponectin level exhibited approximately $93 \%$ and 96\% higher risk of cardiovascular and all-cause mortality, respectively. These findings highlight the importance of detecting adiponectin level for the prediction of cardiovascular and all-cause mortality in CAD patients. However, elevated total adiponectin level was not associated with an increased risk of MACE in CAD patients.

The association of adiponectin level with cardiovascular and all-cause mortality risk has been confirmed in previous meta-analysis $[5,6]$. However, these two metaanalyses did not focus on the CAD patients. Similarly, our study demonstrated the prognostic role of adiponectin for predicting cardiovascular and all-cause mortality in CAD patients. Results from the previous and our meta-analyses raise a clinical question that whether reducing adiponectin level by medication may improve the survival outcomes of CAD patients. Moreover, we further investigated the association of elevated adiponectin level with MACE risk. Overall, our meta-analysis did not observe a significant association between elevated adiponectin level and MACE.
CAD is a heterogeneous clinical conditions, which spans from angina pectoris to acute myocardial infarction. Adipokine level varies acoss the type of CAD. Serum adiponectin level was lower in AMI patients as compared to stable CAD patients [23]. In subgroup analyses, there was a close association of elevated adiponectin level with MACE risk in this subgroup with ACS patients. A potential explanation for this finding may be that higher level of adiponectin in ACS represents a compensatory response to against acute inflammatory and hypoxia-reoxygenation lesions [24]. Moreover, the effect of elevated adiponectin follow-up duration level on MACE was strengthened with the lengthening of the follow-up duration.

Several studies analyzing blood adiponectin level by continuous data also showed a significant association of elevated adiponectin level with adverse cardiovascular outcomes. A prospective study [25] indicated that per 1 standard deviation increment of log-transformed plasma adiponectin was independently predictive of the subsequent risk of all-cause mortality, cardiac mortality, and myocardial infarction in CAD patients. In patients with ACS, adiponectin was associated with higher risk for MACE (adjusted HR 1.08/increment of 1000) [26]. In addition, per tertile increase [27] or unit increment of log-transformed [28] adiponectin level also predicted all- 


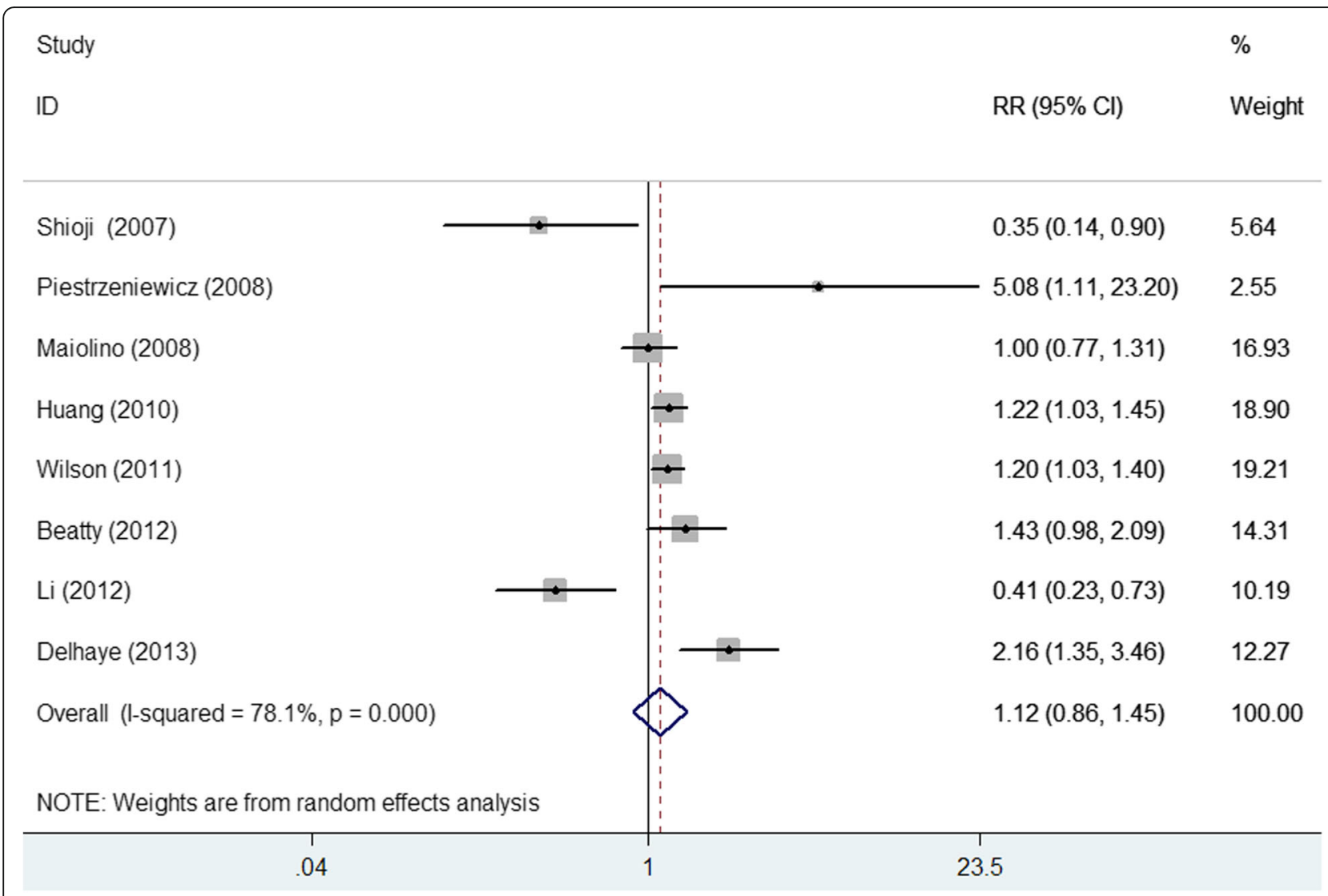

Fig. 2 Forest plots showing pooled RR with 95\% Cl of major cardiovascular events for the highest vs. the lowest adiponectin level in a random effect model

Table 3 Subgroup analyses on major cardiovascular events

\begin{tabular}{|c|c|c|c|c|}
\hline Subgroup & No. of studies & Pooled risk ratios & 95\% confidence intervals & Heterogeneity between studies \\
\hline \multicolumn{5}{|l|}{ Sample sizes } \\
\hline$<500$ & 6 & 1.07 & $0.76-1.54$ & $p<0.001 ;\left.\right|^{2}=83.0 \%$ \\
\hline$\geq 500$ & 2 & 1.16 & $0.82-1.65$ & $p=0.130 ; I^{2}=56.5 \%$ \\
\hline \multicolumn{5}{|c|}{ Type of patients } \\
\hline All CAD & 2 & 0.67 & $0.28-1.59$ & $p=0.006 ; I^{2}=86.8 \%$ \\
\hline ACS & 3 & 1.23 & $1.03-1.47$ & $p=0.180 ; I^{2}=41.7 \%$ \\
\hline \multicolumn{5}{|c|}{ Follow-up duration } \\
\hline$<3$ years & 4 & 0.84 & $0.36-1.97$ & $p<0.001 ; 1^{2}=86.5 \%$ \\
\hline$\geq 3$ years & 4 & 1.31 & $1.02-1.68$ & $p=0.038 ; I^{2}=64.5 \%$ \\
\hline \multicolumn{5}{|c|}{ Adjustment of LVEF } \\
\hline Yes & 5 & 1.24 & $0.72-2.12$ & $p<0.001 ; 1^{2}=84.1 \%$ \\
\hline No & 3 & 1.11 & $0.86-1.44$ & $p=0.034 ; I^{2}=70.3 \%$ \\
\hline \multicolumn{5}{|c|}{ Newcastle-Ottawa Scale } \\
\hline$\geq 7$ stars & 6 & 1.01 & $0.71-1.44$ & $p<0.001 ; I^{2}=82.2 \%$ \\
\hline$<7$ stars & 2 & 2.02 & $0.53-7.70$ & $p=0.068 ; I^{2}=70.1 \%$ \\
\hline
\end{tabular}




\begin{tabular}{|c|c|c|c|}
\hline \multirow{2}{*}{$\begin{array}{l}\text { Study } \\
\text { ID }\end{array}$} & & \multicolumn{2}{|r|}{$\%$} \\
\hline & & $\mathrm{RR}(95 \% \mathrm{Cl})$ & Weight \\
\hline \multicolumn{4}{|l|}{ A.All-cause mortality } \\
\hline Pilz (2006) & $\longrightarrow$ & $2.04(1.53,2.71)$ & 39.39 \\
\hline Wilson (2011) & & $1.57(0.95,2.58)$ & 12.90 \\
\hline Beatty (2012) & $\longrightarrow$ & $1.77(1.12,2.67)$ & 17.06 \\
\hline Lindberg (2012) & 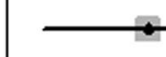 & $2.70(1.30,5.60)$ & 6.04 \\
\hline Hascoet (2013) & $\longrightarrow$ & $1.71(1.16,2.52)$ & 21.39 \\
\hline Pratesi (2016) & & $6.50(2.40,17.70)$ & 3.22 \\
\hline Subtotal $(\mathrm{I}$-squared $=35.8 \%, \mathrm{p}=0.168$ ) & & $1.96(1.64,2.34)$ & 100.00 \\
\hline \multicolumn{4}{|l|}{ B.Cardiovascular mortality } \\
\hline Pilz (2006) & & $2.14(1.52,3.02)$ & 42.36 \\
\hline Maiolino (2008) & $\rightarrow$ & $1.37(0.86,2.17)$ & 23.31 \\
\hline Lindberg (2012) & & $2.57(1.46,4.50)$ & 15.76 \\
\hline Hascoet (2013) & $\longrightarrow$ & $1.86(1.11,3.13)$ & 18.58 \\
\hline Subtotal $($ I-squared $=13.5 \%, p=0.325)$ & & $1.93(1.55,2.42)$ & 100.00 \\
\hline $\begin{array}{c}1 \\
.05\end{array}$ & 1 & & \\
\hline
\end{tabular}

cause mortality in patients with AMI. These findings further supported the prognostic role of adiponectin level for predicting adverse outcomes in CAD patients.

The mechanisms underlying the prognostic utility of adiponectin in CAD patients remain unclear. One potential explanation is that elevated adiponectin level may reflect the severity of coronary lesions. Another explanation for the prognostic role of elevated adiponectin level with worse clinical outcomes may be adiponectin resistance $[29,30]$.

Several potential limitations of this meta-analysis should be noted. First, measurement of adiponectin level at baseline and lack of serial determination may have led to misclassification of the category of patients. Second, the cutoff value of adiponectin elevation varied between studies and we failed to determine the optimal threshold of higher adiponectin level. Third, significant heterogeneity was observed in pooling MACE outcome. Different subtypes of CAD, threshold of adiponectin elevation and length of follow-up were partly responsible for betweenstudy heterogeneity. Fourth, due to the distinct units of adiponectin level increment, we did not evaluate the prognostic value of adiponectin level by continuous data. Finally, our meta-analysis only investigated the prognostic value of total adiponectin level and more studies are necessary to examine the prognostic role of various isoforms of adipocytokines, such as leptin, visfatin and resistin or the high-molecular weight isoform [31].

\section{Conclusions}

This meta-analysis demonstrates that elevated total adiponectin level is possibly an independent predictor of cardiovascular and all-cause mortality in CAD patients. Measurement of total adiponectin level has potential to improve the prediction of cardiovascular and all-cause mortality in these patients. Future studies are warranted to evaluate the prognostic significance of adiponectin level is different between ACS and stable CAD patients. 


\section{Supplementary information}

Supplementary information accompanies this paper at https://doi.org/10. 1186/s12944-019-1168-3.

Additional file 1. Search strategy developed for the meta-analysis.

\section{Abbreviations}

ACS: Acute coronary syndrome; CAD: Coronary artery disease; Cl: Confidence interval; MACE: Major adverse cardiovascular events; NOS: Newcastle-Ottawa Scale: RR: Risk ratio

\section{Acknowledgements}

Not applicable.

\section{Authors' contributions}

LL Yang contributed to study and guaranteed the integrity of study. B Li and Y Zhao searched the literature, extracted data, assessed the study quality, and performed the statistical analysis. ZY Zhang drafted the manuscript and $B$ Li revised the manuscript. All the authors approved the final version of manuscript to be published.

\section{Funding}

None.

\section{Availability of data and materials}

All data generated or analyzed during this study are included in this article.

\section{Ethics approval and consent to participate}

Not applicable.

\section{Consent for publication}

Not applicable.

\section{Competing interests}

The authors declare that they have no competing interests.

Received: 15 August 2019 Accepted: 9 December 2019

Published online: 23 December 2019

\section{References}

1. Benjamin EJ, Blaha MJ, Chiuve SE, Cushman M, Das SR, Deo R, de Ferranti SD, Floyd J, Fornage M, Gillespie C, et al. Heart disease and stroke Statistics2017 update: a report from the American Heart Association. Circulation. 2017;135(10):e146-603

2. Schiele F, Ecarnot F, Chopard R. Coronary artery disease: Risk stratification and patient selection for more aggressive secondary prevention. Eur J Prev Cardiol. 2017:24(3 suppl):88-100.

3. Lau WB, Ohashi K, Wang Y, Ogawa H, Murohara T, Ma XL, Ouchi N. Role of Adipokines in cardiovascular disease. Circulat J. 2017:81(7):920-8.

4. Kishida K, Funahashi T, Shimomura I. Adiponectin as a routine clinical biomarker. Best Pract Res Clin Endocrinol Metab. 2014;28(1):119-30.

5. Scarale MG, Fontana A, Trischitta V, Copetti M, Menzaghi C. Circulating adiponectin levels are paradoxically associated with mortality rate. A systematic review and meta-analysis. J Clin Endocrinol Metab. 2018. https:// doi.org/10.1210/jc.2018-01501.

6. Wu ZJ, Cheng YJ, Gu WJ, Aung LH. Adiponectin is associated with increased mortality in patients with already established cardiovascular disease: a systematic review and meta-analysis. Metab Clin Exp. 2014:63(9):1157-66.

7. Pilz S, Mangge H, Wellnitz B, Seelhorst U, Winkelmann BR, Tiran B, Boehm BO, Marz W. Adiponectin and mortality in patients undergoing coronary angiography. J Clin Endocrinol Metab. 2006;91(11):4277-86.

8. Shioji K, Moriwaki S, Takeuchi Y, Uegaito T, Mutsuo S, Matsuda M. Relationship of serum adiponectin level to adverse cardiovascular events in patients who undergo percutaneous coronary intervention. Circulat J. 2007:71(5):675-80

9. Piestrzeniewicz K, Luczak K, Goch JH. Value of blood adipose tissue hormones concentration--adiponectin, resistin and leptin in the prediction of major adverse cardiac events (MACE) in 1-year follow-up after primary percutaneous coronary intervention in ST-segment elevation acute myocardial infarction. Neuro Endocrinol Lett. 2008;29(4):581-8.
10. Huang SS, Huang PH, Chen YH, Chiang KH, Chen JW, Lin SJ. Association of adiponectin with future cardiovascular events in patients after acute myocardial infarction. J Atheroscler Thromb. 2010;17(3):295-303.

11. Li Q, Lu Y, Sun L, Yan J, Yan X, Fang L, Li M, Fan Z. Plasma adiponectin levels in relation to prognosis in patients with angiographic coronary artery disease. Metab Clin Exp. 2012;61(12):1803-8.

12. Maiolino G, Cesari M, Sticchi D, Zanchetta M, Pedon L, Antezza K, Pessina AC, Rossi GP. Plasma adiponectin for prediction of cardiovascular events and mortality in high-risk patients. J Clin Endocrinol Metab. 2008;93(9):3333-40.

13. Wilson SR, Sabatine MS, Wiviott SD, Ray KK, De Lemos JA, Zhou S, Rifai N, Cannon CP, Morrow DA, Group TS. Assessment of adiponectin and the risk of recurrent cardiovascular events in patients presenting with an acute coronary syndrome: observations from the pravastatin or atorVastatin evaluation and infection trial-thrombolysis in myocardial infarction 22 (PROVE IT-TIMI 22). Am Heart J. 2011;161(6):1147-55 e1141.

14. Beatty $A L$, Zhang MH, Ku IA, Na B, Schiller NB, Whooley MA. Adiponectin is associated with increased mortality and heart failure in patients with stable ischemic heart disease: data from the heart and soul study. Atherosclerosis. 2012;220(2):587-92.

15. Moher D, Liberati A, Tetzlaff J, Altman DG. Preferred reporting items for systematic reviews and meta-analyses: the PRISMA statement. Ann Intern Med. 2009;151(4):264-9 W264.

16. Wells G, Shea B, O'Connell D, Peterson J, Welch V, Losos M, Tugwell P: The Newcastle-Ottawa Scale (NOS) for assessing the quality if nonrandomized studies in meta-analyses. http://www.ohri.ca/programs/clinical_ epidemiology/oxford.asp (Accessed 5 Aug 2019).

17. Begg CB, Mazumdar M. Operating characteristics of a rank correlation test for publication bias. Biometrics. 1994;50(4):1088-101.

18. Egger M, Davey Smith G, Schneider M, Minder C. Bias in meta-analysis detected by a simple, graphical test. BMJ. 1997;315(7109):629-34

19. Lindberg S, Pedersen SH, Mogelvang R, Bjerre M, Frystyk J, Flyvbjerg A, Galatius S, Jensen JS. Usefulness of adiponectin as a predictor of all cause mortality in patients with ST-segment elevation myocardial infarction treated with primary percutaneous coronary intervention. Am J Cardiol. 2012;109(4):492-6.

20. Delhaye C, Kpogbemabou N, Modine T, Lemesle G, Staels B, Mahmoudi M, Tailleux A, Luc G, Bauters C, Lablanche JM, et al. Long-term prognostic value of preprocedural adiponectin levels in patients undergoing percutaneous coronary intervention. Int J Cardiol. 2013;168(5):4921-4.

21. Hascoet S, Elbaz M, Bongard V, Bouisset F, Verdier C, Vindis C, Genoux A, Taraszkiewicz D, Perret B, Galinier M, et al. Adiponectin and long-term mortality in coronary artery disease participants and controls. Arterioscler Thromb Vasc Biol. 2013;33(1):e19-29.

22. Pratesi A, Di Serio C, Orso F, Foschini A, Bartoli N, Marella A, Fumagalli S, Di Bari M, Marchionni N, Tarantini F, et al. Prognostic value of adiponectin in coronary artery disease: role of diabetes and left ventricular systolic dysfunction. Diabetes Res Clin Pract. 2016;118:58-66.

23. Grzywocz P, Mizia-Stec K, Wybraniec M, Chudek J. Adipokines and endothelial dysfunction in acute myocardial infarction and the risk of recurrent cardiovascular events. J Cardiovasc Med. 2015:16(1):37-44.

24. Rathmann W, Herder C. Adiponectin and cardiovascular mortality: evidence for "reverse epidemiology". Horm Metab Res. 2007:39(1):1-2.

25. Cavusoglu E, Ruwende C, Chopra V, Yanamadala S, Eng C, Clark LT, Pinsky DJ, Marmur JD. Adiponectin is an independent predictor of all-cause mortality, cardiac mortality, and myocardial infarction in patients presenting with chest pain. Eur Heart J. 2006;27(19):2300-9.

26. Oliveira GB, Franca JI, Piegas LS. Serum adiponectin and cardiometabolic risk in patients with acute coronary syndromes. Arq Bras Cardiol. 2013:101(5):399-409.

27. Lee SH, Ha JW, Kim JS, Choi EY, Park S, Kang SM, Choi D, Jang Y, Chung N. Plasma adiponectin and resistin levels as predictors of mortality in patients with acute myocardial infarction: data from infarction prognosis study registry. Coron Artery Dis. 2009;20(1):33-9.

28. Ritsinger V, Brismar K, Malmberg K, Mellbin L, Nasman P, Ryden L, Soderberg S, Tenerz A, Norhammar A. Elevated levels of adipokines predict outcome after acute myocardial infarction: a long-term follow-up of the glucose tolerance in patients with acute myocardial infarction cohort. Diab Vasc Dis Res. 2017;14(2):77-87.

29. Engin A. Adiponectin-resistance in obesity. Adv Exp Med Biol. 2017:960:415-41. 
30. Wang Y, Ma XL, Lau WB. Cardiovascular Adiponectin resistance: the critical role of Adiponectin receptor modification. Trends Endocrinol Metab. 2017;28(7):519-30

31. Schaffler A, Muller-Ladner U, Scholmerich J, Buchler C. Role of adipose tissue as an inflammatory organ in human diseases. Endocr Rev. 2006;27(5):449-67.

\section{Publisher's Note}

Springer Nature remains neutral with regard to jurisdictional claims in published maps and institutional affiliations.

Ready to submit your research? Choose BMC and benefit from:

- fast, convenient online submission

- thorough peer review by experienced researchers in your field

- rapid publication on acceptance

- support for research data, including large and complex data types

- gold Open Access which fosters wider collaboration and increased citations

- maximum visibility for your research: over $100 \mathrm{M}$ website views per year

At BMC, research is always in progress.

Learn more biomedcentral.com/submissions 